\title{
Self-Hypnosis and Pain
}

\author{
Dalamagka $\mathbf{M}^{1 *}$ and Kimoglou $\mathrm{D}^{2}$ \\ ${ }^{1}$ Anaesthesiology department General Hospital of Larissa, Greece \\ ${ }^{2}$ Psychologist, USA
}

*Corresponding author: Dalamagka M, Anaesthesiology department General Hospital of Larissa, Greece

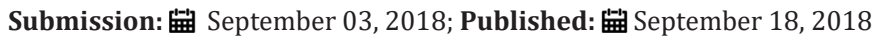

\section{Opinion}

The possibilities of self-suction can be particularly useful in the management of pain. It is possible to modify the experience of pain. The only obstacle is the limits of imagination, but as you surely know the imagination knows little boundaries. Sometimes deep relaxation can help, before giving to yourself the suggestions you need. Other times just let yourself travel and become one with these submissions and so you can be led into a trance state without deep relaxation. What is trance? Trance is not a mystical experience that only trained hypnotists can induce. It's part of our everyday life. If you ever drive a car, you suddenly discovered that you were driving for miles without realizing it, you will understand what is going on (as can happen and reading a good book). It is often described as «the loss of sense of time.» The secret is to gain some experience, so you have control over knowing what to do when you get into a trance state. It is an opportunity to gain control of physics and emotional experience of pain. Efficacy using self-hypnosis is a matter of exercise. It would help experiment with different approaches and find one that suits you best and which one is most useful. Before you begin, make a review of the pain experience. Is there any good reason why you want to stay in this situation? Does it offer you something like attention or relaxation? in this way you will decide that you want to make the difference. When you first start, it would be good to do it at a time when the pain is not so bad. When you become more familiar with self-esteeming approaches, it will be easier to use it when the pain is more intense. It has been reported that the duration of analgesia is increasing day by day. It is helpful to think about the possibility of decrease, rather than disappearance of pain. So, if you imagine a ladder from 1-10, and if you start by classifying your pain at level 7 , then your purpose will be to decrease it to 5 or 4 . By reaching this level you will feel more comfortable. With time you will find yourself reducing pain levels to 2 or 3 . You may still see your pain touching 0 . This will be great. And even if you reduce your pain to some level, see the difference between the two levels of pain and reward yourself for the control you have achieved.

\section{Basic Approaches}

\section{Pain management techniques}

Modifying the physical experience Think of some ways you can change the physical experience of pain, for example: Imagine that the affected area of your body is under the influence of a powerful analgesic such as Novocaine. In some kinds of headaches, it helps to imagine your hands becoming warm and heavy (repeat to yourself: my hands become warm and heavy). Continue to feel this warmth at your feet and fingers (the headaches can recede, directing the blood flow away from the head and the limbs). Bring to your memory situations that cause you analgesia: Think of the feeling of ice in the affected area or on the other hand the feeling of warmth. Recall the analgesic effects of an analgesic. Keep in your memory, all the senses, what you saw, what you were listening to and what I felt.

\section{Modifying the perception of pain}

Think of some ways through which you see yourself perceiving the pain in a different way. See yourself as an injured marathon runner who is determined to continue to the end. Modifying the reference words: If the way described in the physical experience is changed, the way we perceive the pain will change. For example: Instead of the word "pain», we can use the term "narrative» sensation or «vibration» Separation: See your pain as a third person. You may decide to analyze the sensation of pain and then compare the afflicted area with another non-painful spot (this way you can start focusing on non-painful areas).

\section{Removal of attention}

We can keep our minds busy in other things for example: Imagine that you are somewhere that is very relaxing for you (like a beach or a garden). It has focused your attention on this experience - see all the things you saw. All the sounds you heard, smelled, tasted and seen all the beautiful feelings you had. Put it in a part of your body that feels comfortable. Just analyze how it feels this part of your body. Notice how warm or cool this part of 
your body feels. Observe your senses and change from minute to minute. Understand how your heart and mind play a part in your body's function and the perception of pain. The abovementioned techniques are just the beginning. Once you discover how powerful ally your mind is in modifying the pain experience, then the portal for the proposed submissions will open.

\section{Pain control experiment with the following}

Scratch your body ... gather all the pains on a ball ... start to change its size ... give it the margin to become as big as it can ... now make the smaller ... see how small you can do it ... it is possible to get closer size of a sand dot ... moved it in some directions ... now let it move slowly out of the body, moving more and more in every exhalation. Notice how you feel with every exhalation as the pain moves away ... see it disappear at a distant distance. See yourself lying beside the waters of a deep blue sea. Let yourself slip into the cool, soft water and swim slowly. Feel every pain leaving your body and falling to the bottom of the sea...

Let yourself swim until you feel completely relaxed and comfortable ... then come to the shore and go out to the sand. Communicate with your pain: See yourself in a beautiful, peaceful landscape ... Find the pain and ask him to come, to communicate with you ... let the pain take some forms like a small creature with a friendly face... Let it say what it is and listens to with respect and with an open mind... Give him his positive intentions. Once you discover the lesson he has come to give you and share with you, thank him and tell him that you have learned enough... Keep the creature to give a sweet smile and go away, your goal was completed I do not need to communicate further with you through the pain. Imagine going down with an elevator that leads you out of full alertness to your subconscious .. see the elevator door open and find yourself in a huge corridor with many doors ... Imagine moving into the corridor and seeing many doors, each one brings a part of your body as a name ... Go to the door to the door that has the name, the part of your body that is the source of the pain... Hit the door and imagine the door open in front of you... Imagine you are welcome to the room and let yourself have a conversation with this part of your body, let it tell you that it needs you. When you finish the conversation, thank this place, leave the room and return to the elevator ... leave yourself to climb up, until you return to full alert again. 3. Flashback
With the flashback, you go back to the time before the pain appears. Take a moment to let yourself relax, perhaps by focusing on your breath for a while. Go back time where there was no pain. For example, if you have arthritis: Remember the time before arthritis starts when your legs were not painful. Think about walking around home or on vacation. Remember how fun it was to dance, run or swim. Let yourself get in make good memories, use all your senses to see, hear and live every moment ... and notice what your feet feel (you can remember them so lightly, hot or cool, or loud or relaxed) For example: «I can discover that in remembering this wonderful time, my feet have a sense of coolness and are light. I can find out that this comfort on my feet lasts for a short time or maybe lasts longer than I thought» See the difference in minor changes in the quality of pain and encourage yourself to continue. Loss of sense of time: This can be a useful technique if there are periods of time when the pain is more intense and sometimes it is minimal or minimal. It is due to our ability, when we feel good, to lose the sense of time and to discover that time has passed faster, without realizing it. Use this approach when you feel relatively comfortable and with less pain. Let yourself relax deeply and prepare for selfdenial.

Let yourself focus on the moment you feel comfortable. Think of some moments that will give you the idea of lengthening time, like the most enjoyable vacation you had or the pleasant feeling you had when watching your favorite movie. be fun to see how long that feeling can last. Another approach is to imagine a journey«I can imagine that I make a long journey, passing through many cities. And every city has a station that I can stop and rest. I feel comfort and relaxation at the first station now. Maybe this feeling of comfort and the level of relief will last until the next station. And by looking at the street, I almost see the lights of the next city and its next station. I may find that the distance to the next town is smaller than I imagined, and I can be surprised to notice that I still feel comfortable, as at the first station. I can find the station getting closer and shorter. « Let the journey last as long as you want and fill the gap between the cities with images you can see along the way. Self-stimulation is an opportunity to use your creative mind in all its splendor, in the service of your good physical and emotional development.

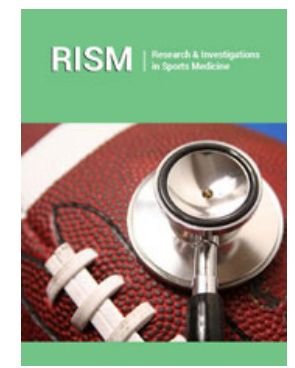

Research \& Investigations in Sports Medicine

Benefits of Publishing with us

- High-level peer review and editorial services

- Freely accessible online immediately upon publication

- Authors retain the copyright to their work

- Licensing it under a Creative Commons license

- Visibility through different online platforms 